Since January 1950, about two dozen posts of research assistant or demonstrator have been approved in London and the home counties. Most of these have now been filled, and at about a dozen colleges research by staff and advanced students is accepted as a normal part of the curriculum. At other colleges, research by members of the staff is recorded and the report emphasizes that staff of the calibre required will never be attracted unless some opportunity for original research is provided. The close contact of the staff with neighbouring firms should avoid any difficulty in suggesting lines of investigation likely to be of service to local firms, nor should members of the staff necessarily be required to carry out such research on the college premises.

The evidence shows that departments of chemistry have usually found it easier to provide facilities for research than have departments of engineering, and that the principal obstacle to the further development of industrial research in many technical colleges, even the largest, is lack of laboratory space. This position is attributed partly to the simpler apparatus and less space required in chemical research than in engineoring research, and partly also to the absence of sufficient workshop staff; and the Council recommends that the needs of the engineering industry should be kept in mind in allocating research demonstratorships. It also urges authorities to press forward especially with extension plans for those departments in which the standard of work shows that more research could.be undertaken successfully in co-operation with industry. Commenting on the circumstances in which staff should be given relief from teaching duties, the Council sees no objection to lecturers undertaking consulting work, and would support ad hoc investigations in colleges by members of the staff which are not of the kind that normally lead to publication; it also stresses the importance of personal relations between the colleges and industry.

\section{THE AMERICAN PHYSICAL SOCIETY}

\section{REPORT FOR 1953}

\section{T} HE 1954 annual meeting of the American Physical Society was held at Columbia University, New York City, during January 28-30, and the twenty-third annual meeting of the American Association of Physics Teachers was held simultaneously at Columbia University, Barnard College, and the City College of Now York. At the joint coremonial session of the two bodies on January 29 , the retiring presidential address of the American Physical Society was delivered by Prof. E. Fermi, of the University of Chicago, who spoke on "What can we Learn with High-energy Accelerators?" The 1953 Oersted Medal of the American Association of Physics Teachers was presented to Prof. C. N. Wall, of the University of Minnesota (Amer. J. Phys., 22, 363 ; 1954). The twelfth Richtmyer Memorial Lecture was delivered by Prof. J. A. Wheeler, of Princeton University, who took as his subject "Fields and Particles". At the joint banquet which followed, the after-dinner speakers were Prof. Grayson Kirk, president of Columbia University, who discussed the position of physics in the social structure, Prof. Leon Brillouin, of International Business Machines Corporation, who spoke of Prof. H. A. Lorentz, and Prof. S. A. Korff, of New York University, who referred to the International Geophysical Year and recounted some of his experiences in a highaltitude Iaboratory in northern Alaska. 'The second O. E. Buckley Solid-State Physics Prize was presented to Dr. J. Bardeen, of the University of Illinois, for his outstanding contributions to semiconductor research.

At the business meeting of the Society it was reported that the total membership had reached 11,200 , the financial position was satisfactory and that the Physical Review continued to expand. The following were elected to hold office for 1.954: President, H. A. Bethe; Vice-President, R. T. Birge ; Secretary, K. K. Darrow ; and Treasurer, G. B. Pegram. The annual meeting was again a very large one, with a registration of 2,100 and with more than three hundred contributed papers. Columbia University, which has been host to the Society on many occasions during the past fifty years and in particular for eleven of the past twelve annual meetings, has now reluctantly admitted that such a large convention involves too great a burden, and. accordingly it has been agreed to hold the 1955 annual meeting in hotels in the vicinity of Pennsylvania Station, New York City. As a valedictory to Columbia University and as a tribute, which was made doubly fitting by the fact that 1954 is the bicentennial year of the University, a special session of the annual meeting was devoted to a survey of the University's association with physics and with the American Physical Society. This consisted of four addresses and the presentation of a plaque, to be affixed to 8 wall in the Pupin Physics Laboratories, commemorating the Society's inaugural meeting on May 20, 1899, at Columbia University. Prof. G. B. Pegram reviewed the early years in the history of physics at the University, Prof. E. Fermi the genesis of the nuclear-energy project, Prof. I. I. Rabi the more recent years, and Dr. K. K. Darrow, the Society's secretary, discussed the link between the Society and the University.

The scientific programme of the Physical Society meeting, details of which together with abstracts of the contributed papers are given in the minutes of the meeting (Phys. Rev., 94, 742; 1954), included a joint session of the Division of Fluid Dynamics and the Institute of the Aeronautical Sciences, at which four papers dealing with high-speed flow phenomena were read; four symposia; a group of four papers in which plans for accelerators of the future, including the designs of the $25-\mathrm{BeV}$. proton synchrotron for CERN and a 15-BeV. accelerator, were discussed by E. D. Courant, J. P. Blewett, M. S. Livingston and $H$. G. White; and nineteen invited papers. At the Brookhaven-Nevis symposium the subjects of discussion were the use of the cosmotron as a research tool and the interpretation of high-energy experiments; at the symposium of the Division of Fluid Dynamics there were four papers dealing with aspects of shock waves in liquids and solids; at the symposium of the Division of Electron Physics the conduction mechanism, interface compound formation and noise mechanisms in oxide-coated cathodes together with a review of electronic processes in barium oxide crystals were considered; and at the separate symposium devoted to the subject of nuclear size and density of distribution four differ- 
ent methods of determination were described. Of the invited papers, two, by members of the Bell Telephone Laboratories, dealt with the theory of secondary electrons; two, including a discussion by J. R. Zacharias of precision measurements, with molecular beams; two with the neutrino; three, "Microwave Resonance in Colour Centres", by E. E. Schneider, of the University of Durham, "Polarization of Nuclei in Metals by Magnetic Resonance", by A. W. Overhauser, and "The Solid-State Cyclotron", by C. Kittel, with magnetic resonance; and two with cryogenics. In addition, P. W. Bridgman spoke of the effects of pressure on twelve rare-earth metals, W. A. Pomerantz on cosmic radiation at very high altitudes near the geomagnetic equator, and E. W. Corson on the properties of new $V$-particles.

The programme of the meeting of the American Association of Physics Teachers (Amer. J. Phys., 22, 426 ; 1954) consisted of two panel and one roundtable discussions, three invited papers, twenty-seven contributed papers, a film session and a business moeting in addition to the joint sessions with the Physical Society. C. N. Hoyler, of the Radio Corporation of America, gave a demonstration of colour television in which recent developments of the R.C.A. were described and illustrated. In the panel discussion on "Research Subsidies and College Teaching", various problems involved in combining teaching and research were considered; and in the session devoted to a discussion of the functions and mission of the Association, H. K. Schilling reviewed the history of the Association and T. H. Osgood, editor of the American Journal of Physics, spoke on "What goes into the Journol". At the business meeting of the Association on January 30, it was agreed to confer honorary membership on D. Bronk, former president of Johns Hopkins University, president of the National Research Council and head of the Rockefeller Institute for Medical Research; and for noteworthy service to the Association T. D. Cope, P. Kirkpatrick, C. J. Overbeck and M. H. Trytten were voted special citations. The need for increased income to cover current expenses was emphasized and a change in the by-laws was approved to permit the increase of subscriptions to a maximum of eight dollars per annum. The following were elected to hold office for 1954: President, P. M. Marsh; President-elect, R. R. Palmer ; Treasurer, F. W. Sears ; and Secretary, R. F. Paton.

\section{BREEDING FOR BEEF IN TROPICAL AND SUB-TROPICAL CLIMATES}

CLIMATE, and temperature in particular, is 1 directly concerned with the success or failure of animal production in tropical and sub-tropical territories. It has boen established in various parts of the world that wide variations exist between different breeds and types of farm animals in their ability to adapt themselves to the climatic conditions peculiar to a particular environment. Because of their low powers of adaptability, the introduction of European breeds has failed in most tropical territories, and this has focused the attention of research workers on the wide range of ecological problems confronting the livestock industry in those parts of the world (D. M. Joubert, Colonial Plant and Animal Products, 4, No. 1 ; 1954).
In the breeding of livestock for tropical and subtropical environments, it is important to pay attention to the conformational features and breed characteristics which promote adaptability. First, for maximum radiation to be possible, the animal must possess a large skin area. It is a noticeable feature of cattle native to tropical regions that they have a well-developed dewlap which extends down to the navel, together with easily extensible skin folds which are especially numerous in the neck and thoracic regions. These characters are illustrated in the Afrikaner bull and cow, a tropical breed indigenous to South Africa and belonging to the lateral-horned zebu group. In the zebu cattle of India the ears, too, are considerably larger than those of Bos taurus (European) cattle.

Hair covering, which includes the thickness of the coat and structure of the hair fibre, is of equal importance in heat regulation. The critical temperature of smooth-coated cattle lies several degrees below that of woolly-coated individuals. In recent investigations, Bonsma and his associates have showed that, with the progeny of a mutant woollycoated Afrikaner bull, tropical degeneration is possible also in the native stock should they lack any of the essential attributes which promote adaptability.

Earlier studies showed that a light-coloured coat is superior to black in the dry tropies. White or cream-coloured individuals do even better than reds provided that the hide is protected by pigmentation. Colour is regarded as playing a part in heat regulation by influencing the amount of sunlight that is reflected from the skin. Dark colours presumably tend to increase the heat load of the animal. Measurements of the reflexion of light from various coat colours indicate that the coat of white Afrikaners absorbs about 45 per cent of the solar radiation impinging upon it, as against 89 per cent in the case of the black hairy coat of Aberdeen-Angus cattle, 78 per cent of red Afrikaners, 93 per cent of red Sussex cattle and 50 per cent of cream-coloured Simmenthalers.

The effect of a tropical environment on the conformation of an unadapted beast is shown by comparing an unadapted woolly-coated Shorthorn cow with $\&$ normal individual of similar breeding and age. Whereas the beef Shorthorn is normally a digestive type - that is, relatively round in cross-section and equally deep through both chest and belly-the exotic animal in tropical environments tends to develop into a respiratory type. This may be explained by the fact that the Shorthorn has a limited skin area and also a woolly coat, both lowering its capacity of heat loss. The burden of thermolysis thus falls almost entirely on the water-evaporating capacity of the lungs, and tho obvious conformational change to take place is an increased lateral depth of chest, flattening of ribs and a contracted belly.

Joubert has also considered the effects of the nutritional environment on cattle in tropical countries. In regions with fluctuations in the nutritive value of the natural pastures, as well as with high summer temperatures, the problem of adapting the exotic beast is complicated. As the body tem. perature increases during the hot months, meta. bolism is stepped up, the time spent in grazing is reduced and that of lying in the shade increased. In short, the animal suffers from a constant fever or hyperthermia. If the grazing is exceptionally 